\title{
TRANSPORT RISK IDENTIFICATION AND ASSESSMENT
}

Jaroslava Kubáňová, Iveta Kubasáková*

Department of Road and Urban Transport, Faculty of Operation and Economics of Transport, University of Zilina, Zilina, Slovak Republic

*E-mail of corresponding author: iveta.kubasakova@fpedas.uniza.sk

\section{Resume}

The transport process is characterized by transport operations and the relationships between them, the route, the time of transport and the type of product transported. One of these parameters is the degree of risk associated with a possible disruption of the transport process. Therefore, this article aims to present the possibility of calculating the degree of risk on the selected transport route. The risk level is calculated on based on the actual risk incidents on the transport route.

\section{Article info}

Received 14 January 2021

Accepted 19 January 2021

Online 20 May 2021

\section{Keywords:}

crime, transport, risk matrix, measure

\section{Introduction}

The transport and logistics industry provide one of the most important services of the modern globalized and interconnected world. Since the beginning of 2020 , more and more countries around the world have closed their borders and restricted traffic and travel in order to prevent the outbreak of coronaviruses (COVID19) pandemic, thus creating barriers to international trade and transport. The pandemic affects almost every dimension of economic activity and individuals around the world. Due to the outbreak of coronavirus, the supply chains are limited in the logistics and transport industries, although they are different in the air, freight and maritime sectors. Nevertheless, the risk incidents occur that negatively affect the transport processes.

\subsection{Global cargo crime trends}

According to new research, the insurance company has the largest cargo theft in the world in the field of freight transport, whether it is a criminal activity during the transport or in a parking lot. In the following Figure 1 one can see a comparison of the total criminal activity in transport for selected years in the EMEA region. Most crimes occurred in Germany, France and the United Kingdom.

If one looks at the type of criminal activity, shown in Figure 2, one can notice that the most common criminal activities are theft from vehicle, theft of vehicle, theft of container or robbery. This is followed by theft from facility, fraudulent pick up, hijacking, etc.

There are different ways of parking on roads in Europe, in compliance with the Regulation 561/2006 or the AETR agreement (required rest of professional drivers), [2]. Some use regular public car parks, others park on the side of roads, while those more responsible rely on security car park services. The biggest problem is parking in unsecured parking lots. One can see in Figure 3 the number of attacks at unsecured parking places. Drivers use unsecured parking areas because there are few safe parking lots around the world. Their number in this period is 7500 , which is absolutely insufficient with the growing number of road freight transport.

\section{Risk identification}

Identified risks along with their respective mitigation measures are:

- hijacking - the use of force (armed or unarmed), threat or intimidation to kidnap the driver in order to take the vehicle,

$\square$ impact: loss of cargo, monetary loss, customer dissatisfaction, crew injury,

$\square$ measures: insurance, safety parking spot, security equipment, training,

- robbery - the use of force (armed or unarmed), threat or intimidation in order to steal shipments/ cargo while employees, guards or drivers are present and coerced to allow access (open doors), hand over goods, hand over vehicle,

$\square$ impact: loss of cargo, monetary loss, customer 


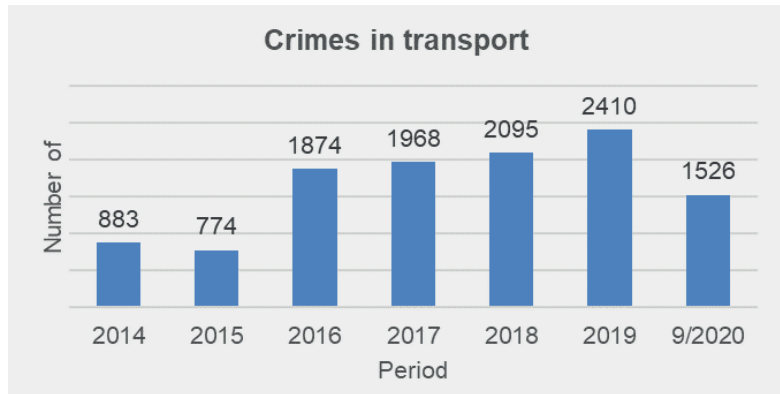

Figure 1 Number of crimes in transport in EMEA region [1]

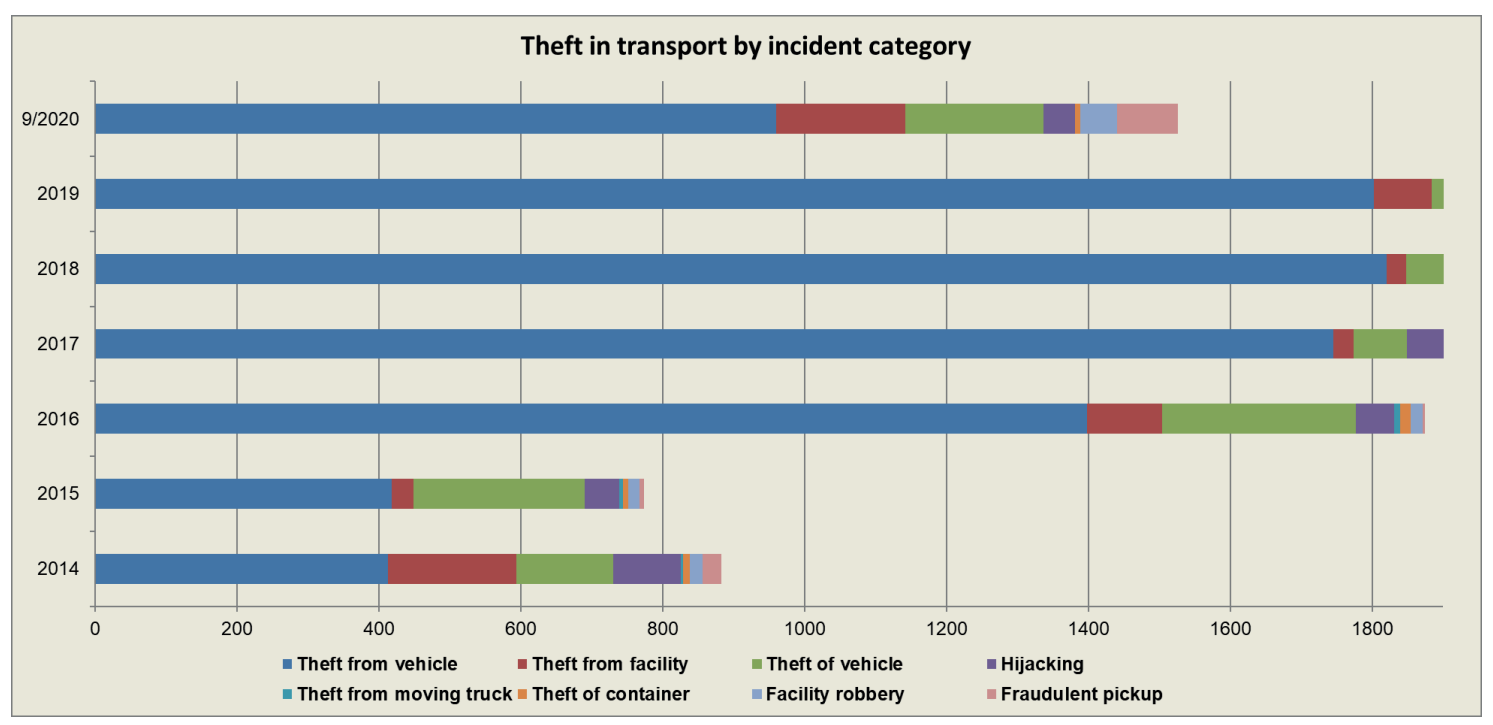

Figure 2 Theft in transport by incident category [1]

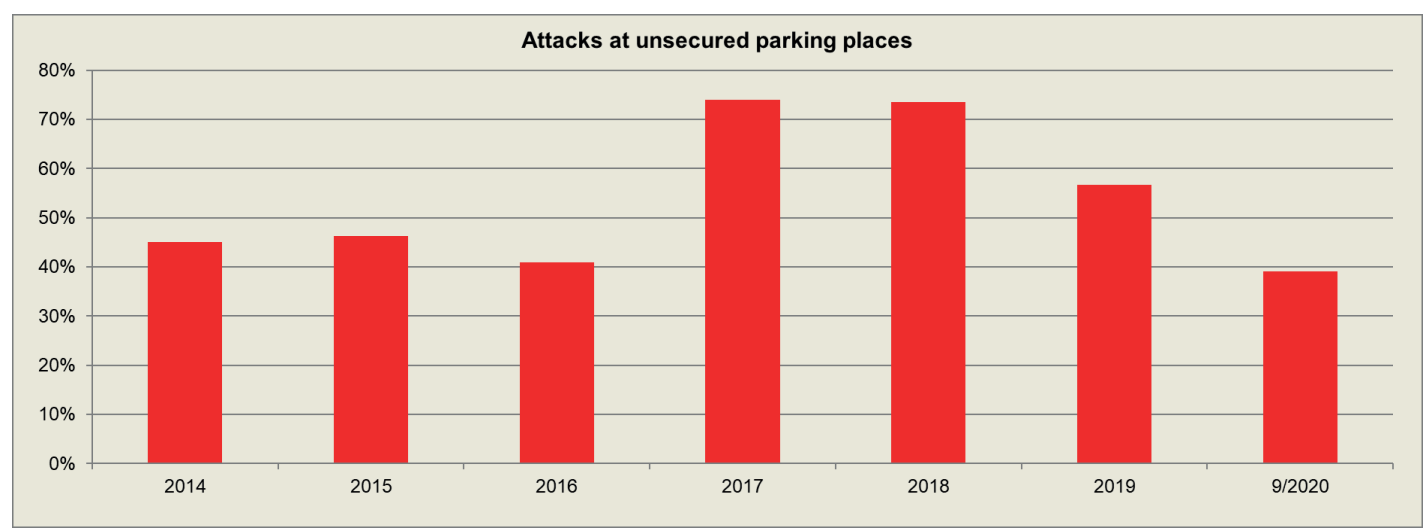

Figure 3 The number of attacks at unsecured parking places [3]

dissatisfaction, crew injury,

$\checkmark$ measures: insurance, safety parking spot, security equipment, training,

- $\quad$ theft - general term for wrongful taking of property without the owner's willful consent,

$\square$ impact: loss of cargo, monetary loss, customer dissatisfaction,

$\square$ measures: insurance, training, safety parking spot, security equipment, trailer door monitoring,

- fraud - theft by deception; offense of deliberately deceiving another in order to damage them - usually, to obtain property or services from the victim unjustly, impact: loss of cargo, monetary loss, customer dissatisfaction,

$\checkmark$ measures: insurance, training, verification of documents, verification of shipper [4-7].

\subsection{Risk assessment matrix}

The purpose of the risk assessment is to analyse and evaluate the identified risks to determine whether they need to be treated. Diagrams or matrices can be used to illustrate risks (See Table 1). This matrix is an example in which risks are assigned priority classes 
Table 1 Risk assessment matrix [7]

\begin{tabular}{|c|c|c|c|c|}
\hline & \multicolumn{4}{|c|}{ risk category } \\
\hline likelyhood / & $\mathrm{I}$ & II & III & IV \\
\hline frequency & catastrophic & critical & marginal & negligible \\
\hline frequent & 1 & 3 & 7 & 13 \\
\hline likely & 2 & 5 & 9 & 16 \\
\hline occasional & 4 & 6 & 11 & 18 \\
\hline remote & 8 & 10 & 14 & 19 \\
\hline unlikely & 12 & 15 & 17 & 20 \\
\hline \multicolumn{2}{|r|}{ risk index } & \multicolumn{3}{|c|}{ risk acceptance category } \\
\hline \multicolumn{2}{|r|}{$1-5$} & \multicolumn{3}{|c|}{ not acceptable } \\
\hline \multicolumn{2}{|r|}{$6-9$} & \multicolumn{3}{|c|}{ not desirable } \\
\hline \multicolumn{2}{|r|}{$10-17$} & \multicolumn{3}{|c|}{ acceptable with extra control } \\
\hline \multicolumn{2}{|r|}{$18-20$} & \multicolumn{3}{|c|}{ acceptable with no extra control } \\
\hline
\end{tabular}

Table 2 Matrix of losses and frequency [7]

\begin{tabular}{|c|c|c|c|c|}
\hline & & losses and violen & & \\
\hline losses / & catastrophic & critical & marginal & negligible \\
\hline frequency & loss $>100001 €$ & $100000 €<\operatorname{loss}<25001 €$ & $25000 €<\operatorname{loss}<1001 €$ & loss $<1000 €$ \\
\hline frequent $>4.75$ & 1 & 3 & 7 & 13 \\
\hline likely $3.5<$ li <4.75 & 2 & 5 & 9 & 16 \\
\hline occasional $2.25<\mathrm{li}<3.5$ & 4 & 6 & 11 & 18 \\
\hline remote $1<$ li $<2.25$ & 8 & 10 & 14 & 19 \\
\hline unlikely $<1$ & 12 & 15 & 17 & 20 \\
\hline
\end{tabular}

created by a combination of their acceptability and consequences. Such tables must be adapted to the needs of a particular organization or risk assessment objective. This risk assessment matrix contains hazards, which are categorized relatively to their degree of criticality among

- Catastrophic

- Critical

- Marginal

- Negligible,

based on their consequences in the activity under investigation. Since the frequency of each potential occurrence is important factor, this assessment risk matrix can be used to codify the risk assignment, which in conjunction with the risk assessment table present the total picture of the threats that company faces, their consequences and likelihood of occurrence [7] (see Table 2).

The risk assessment matrix is characterized according to the colour scheme that best describes the desired security level for each risk situation.

Beyond the qualitative calculation of the likelihood of occurrence for a catastrophic event, there is also the capability for quantitative computation of such a figure, in the case that the valid statistical data are recorded. Furthermore, the use of modern specialized statistical methods and models can offer significant increase in reliability of the calculation of the risk frequency of risks, with a dramatic contribution in the overall reliability of the risk assessment under examination. It is obvious that the calculated risk frequency is a crucial factor. Combined with the factor of Criticality, an organization can find out how urgent a certain risk is and then deal with it, according to the priority it assigns to that risk [8-10].

\subsection{Risk assessment for transport route}

For effective route planning and scheduling, it is necessary for the employees of the transport department to participate in the preparation of the distribution plan, or at least to know and understand it. The vehicle routing and planning process must meet the following objectives:

- maximizing the payload of a vehicle (by maximizing vehicle fill out and back) and maximizing vehicle utilization (by maximizing the number of loaded journeys per vehicle);

- $\quad$ minimizing distance (e.g., minimizing overlapping deliveries) and minimizing time (e.g., minimizing motionless time); and

- meeting the customer requirements in terms of costs, services and time and meeting the legal requirements in terms of vehicle capacity and driver hours [1, 11-13].

If the dispatcher wants to plan a safe transport for the driver, he must consider:

- date and place of loading,

- date and place of unloading,

- type of road infrastructure (highways, urban and 


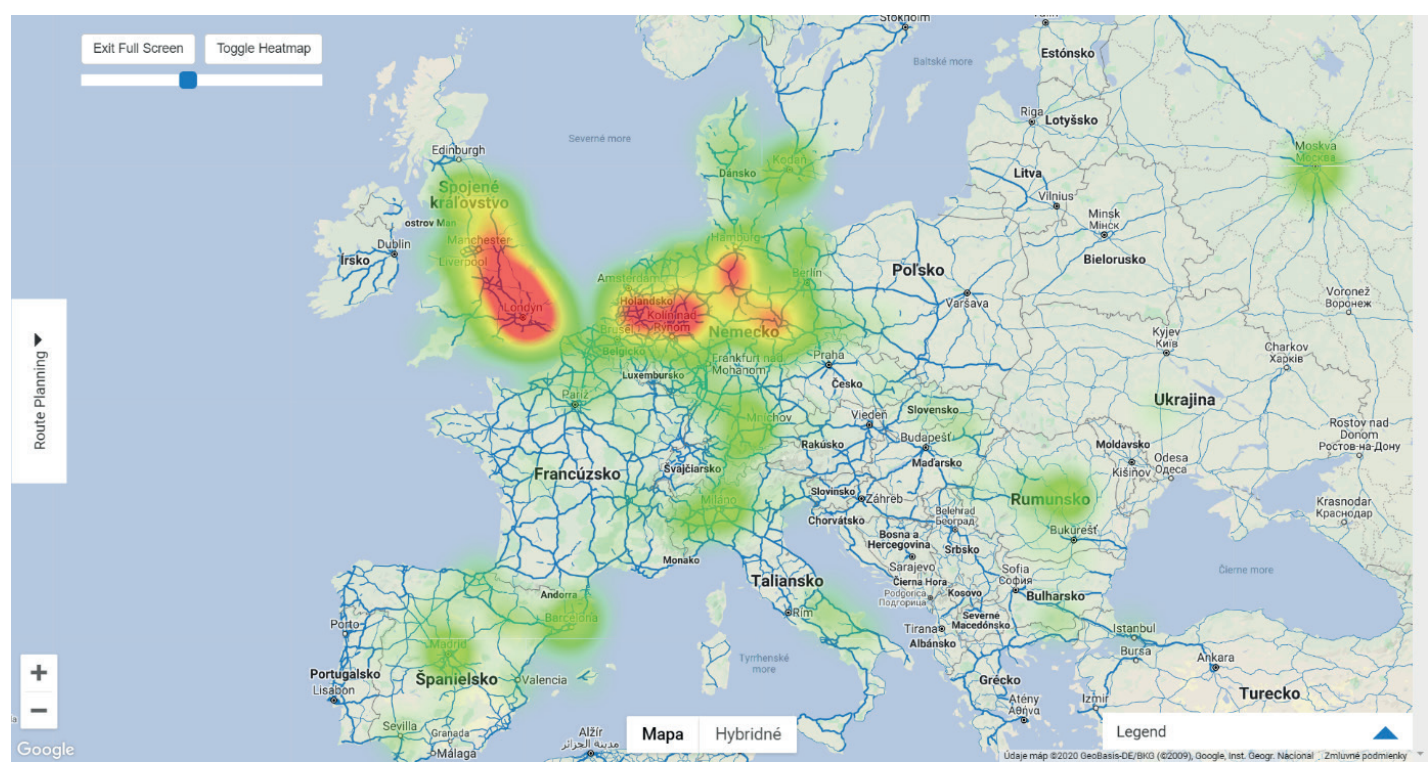

Figure 4 The intensity of cargo crimes in the Europe in February 2020 [15]

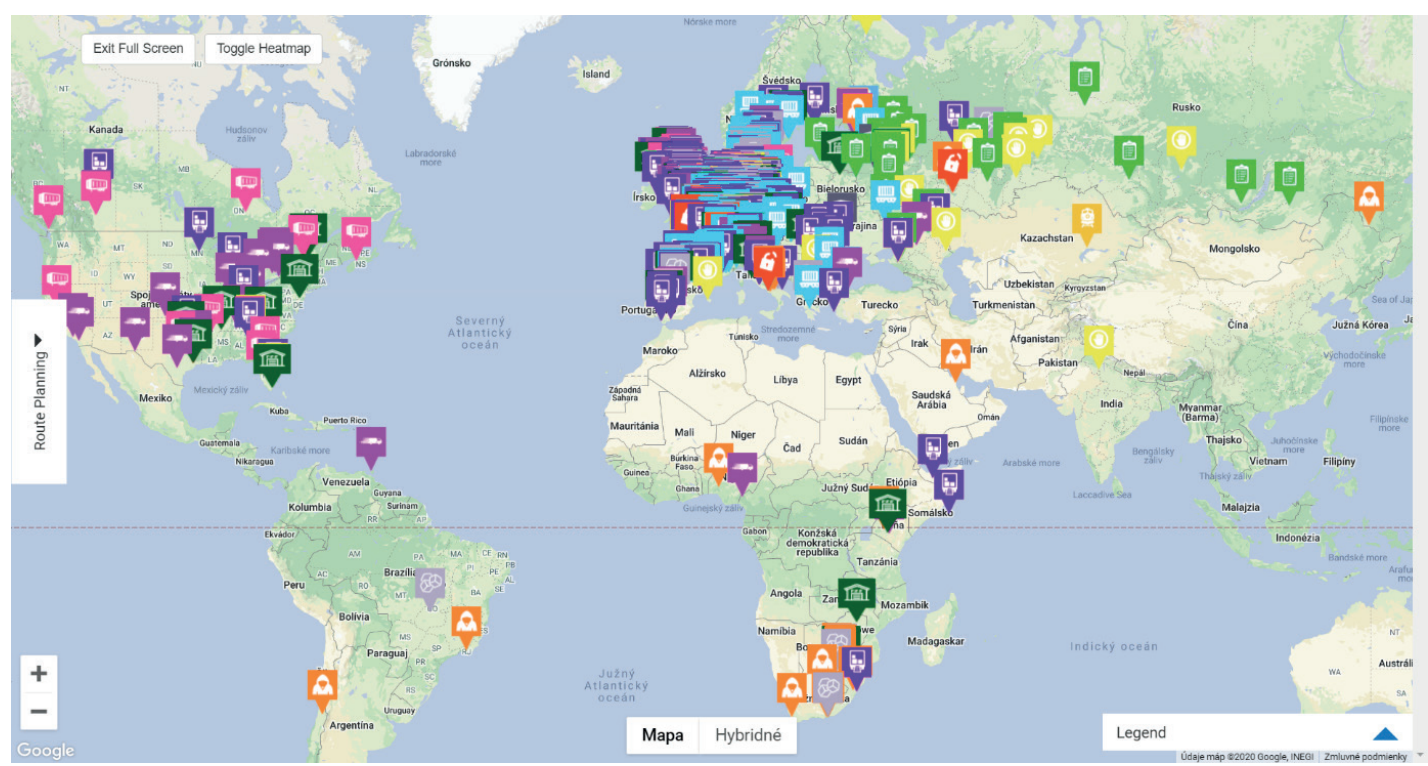

Figure 5 The type of crimes in World in 2020 [3]

rural roads),

- secure parking available,

- driving time restriction,

- risk assessment.

The road infrastructure is important due to the different speed limits and capabilities in place. If it is possible, for the highly valued transportations highways are preferred.

As mentioned above, during the transport, the driver is exposed to several types of risks [7]:

- theft,

- robbery,

- hijacking,

- fraud, etc.

One needs to make a category table of risk:

Incident type:

- $\quad$ Category I - hijacking, robbery, fraud
- $\quad$ Category II - vehicle theft

- Category III - theft from vehicle

- Category IV - other theft (theft of container, theft from facility, ...) Modus operandi:

- Category I - forced stop, violence

- Category II - deceptive stop

- Category III - intrusion

- Category IV - deception Average monetary loss $(€)$ :

- Category I - Loss > $100001 €$

- Category II - $25001 €<$ Loss $<100000 €$

- Category III - $1001 €<$ Loss $<25000 €$

- Category IV - Loss $<1000 €$

Likelihood Index:

This index is calculated based on the following formula: 


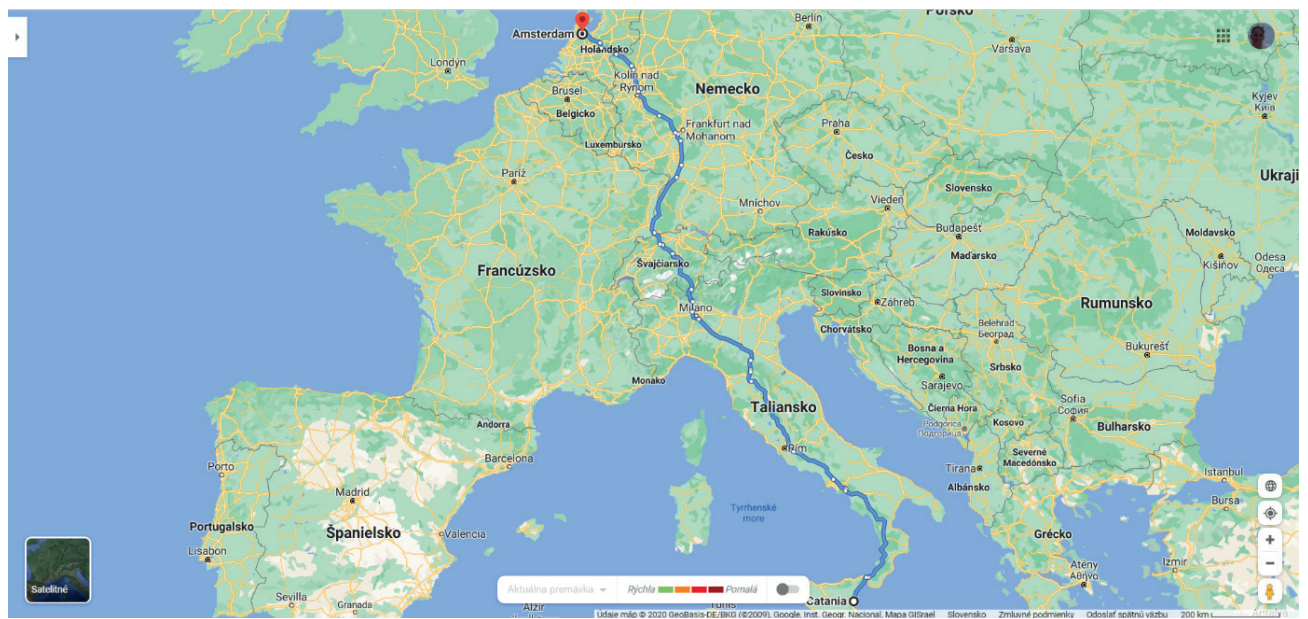

Figure 6 The first transport route from Catania to Amsterdam [3]

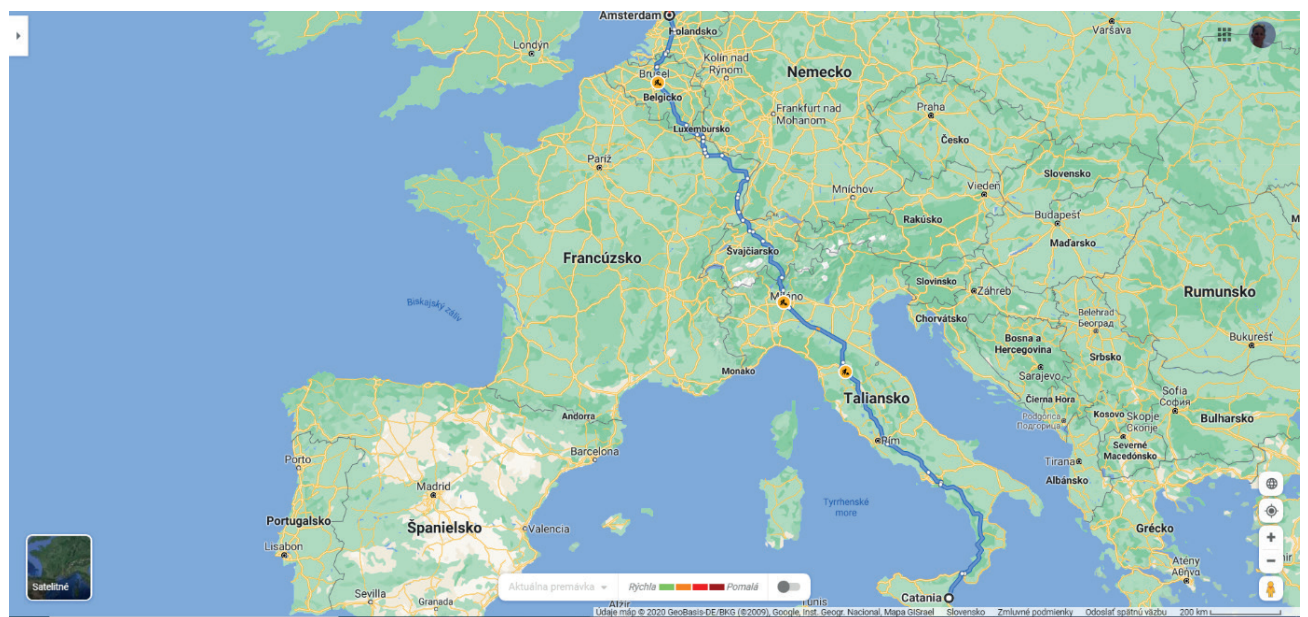

Figure 7 The second transport route from Catania to Amsterdam [3]

likelyhood index $=\frac{\text { index } / \text { years }}{\mathrm{km} / 100}=\frac{\text { index } * 100}{\mathrm{~km} * \text { years }}$,

where:

$\mathrm{km}$ - the length of the route in $\mathrm{km}$,

incidents - the number of incidents across the route, years - the time period that includes the incidents [7].

\subsection{Route planning}

If the carrier wants to plan the transport with regard to safety, he must know the applications that will help him in this. One of them is the TAPA IIS database focused on the safe truck parking places. In addition to information about safety truck parking places, the IIS database also provide information about security incidents classified by several categories, including:

- burglary,

- fraud,

- hijacking,

- robbery,

- theft (theft from vehicle, theft from facility, theft of vehicle, truck theft) $[1,14]$
Modus operandi:

- deception,

- deceptive stop,

- forced stop,

- fraud,

- internal,

- intrusion,

- pilferage,

- $\quad$ violent $[9,15]$.

In Figures 4 and 5 one can see the IIS heatmap tool, wich shows the intensity and type of the cargo crimes in the UK and the Netherlands in the month of February 2020 .

The following example shows how the risk of criminal activity could be reduced by planning a transport route [16]. Two routes from Catania to Amsterdam (see Figures 6 and 7) were chosen. The characteristics of the individual routes are given below.

The data needed for calculation were taken from the IIS Database provided by TAPA. All incidents are reported by the TAPA EMEA members only. For the public, data from the database are provided only for the last 90 days. The complete database is only for members who pay for membership every year. The 
Table 3 Matrix of the first and second route information

\begin{tabular}{ccccccc}
\hline & $\mathrm{kms}$ & countries & incidents & likelihood index & average loss $(€)$ & risk index \\
\hline route 1 & 2416 & 4 & 92 & 7.616 & 68000 & 10 \\
route 2 & 2445 & 6 & 54 & 4.744 & 156000 & 8 \\
\hline
\end{tabular}

$92 * 100 / 2416 * 0.5=7.616$

$58 * 100 / 2445 * 0.5=4.744$

number of accidents on selected routes is for the first

half of 2020 (see Table 3).

\section{Results and discussion}

From the case study one can evaluate the following conclusions:

\section{Route 1:}

Risk index: 10

Through:

- Italy, Switzerland, Germany, Netherland

Countries crossed: 4

Distance: $2416 \mathrm{~km}$

Estimated total duration: 66 hours

Short breaks: 45 min - 4

Long breaks: > 45 min - 3

Number of incident: 92

Likelihood index: 7.616

According to the likelihood index, this risk is classified as Frequent.

\section{Assessment Methodology:}

Average money loss: $68000 €$ from incident reporting money loss.

Category II

Risk acceptance category: Not acceptable

Incident type: $64 \%$ of incidents reporting Incidents type are recorded as Theft from vehicle

Category III

Risk Acceptable category: Not desirable

Modus operandi: $68 \%$ of incidents reporting a modus operandi are recorded as Deception.

Category IV

Risk Acceptable category: Acceptable with extra control

According to the above, route 1 is ranked at 3 for money loss, 7 for incident type and 13 for modus operandi.

\section{Route 2:}

Risk index: 8

Through:

- Italy, Switzerland, France, Luxemburg, Belgium, Netherland

Countries crossed: 6

Distance: $2445 \mathrm{~km}$

Estimated total duration: 67.75 hours

Short breaks: 45 min - 5

Long breaks: $>45$ min - 3

Number of incident: 54

Likelihood index: 4.744

According to likelihood index, this risk is classified as
Likely.

Assessment Methodology:

Average money loss: $156000 €$ from incident reporting money loss.

Category I

Risk acceptance category: Not acceptable

Incident type: $49 \%$ of incidents reporting Incidents type are recorded as Theft from vehicle

Category III

Risk Acceptable category: Not desirable

Modus operandi: $53 \%$ of incidents reporting a modus operandi are recorded as Intrusion.

Category III

Risk Acceptable category: Not desirable

According to the above, route 2 is ranked at 2 for money loss, and 9 for incident type and modus operandi.

\section{Conclusions}

After comparing the two routes, one could come to the following conclusions:

Route 1 is categorized as Not acceptable (3), Not desirable (7) and Acceptable with extra control (13). Route 2 is categorized as Not acceptable (2), Not desirable (9), Not desirable (9).

Route 1 is shorter and scored the same as route II in two categories - Average money loss and Incident type, but in Modus operandi category has an acceptable with extra control. Route 2 is longer and lead across six countries, so probability of the delay at the border is greater.

The security route risk assessment should always be a part of the route planning activity. The road risk assessment applies the standard risk assessment approach to many hazards associated with driving for work, including journey length, allowing enough time for the journey, arrangements to take a break, driving posture, route choice and thinking of alternatives to driving. The risk assessment is beneficial for carriers and their customers and can lead to prevention of possible losses from the risk accidents.

\section{Acknowledgement}

This paper was developed with support of a project: MSVVS SR - VEGA No. 1/0245/20 Poliak, M.: Identification of the impact of a change in transport related legislation on the competitiveness of carriers and carriage safety. 


\section{References}

[1] IIS key glossary - Tapa Emea [online]. Available from: https://www.tapa-global.org/intelligence/iis-data-resource/ iis-key-glossary.html

[2] Regulation (EC) no 561/2006 on the harmonisation of certain social legislation relating to road transport and amending Council Regulations (EEC) No 3821/85 and (EC) No 2135/98 and repealing Council Regulation (EEC) No 3820/85 [online]. Available from: https://eur-lex.europa.eu/legal-content/EN/TXT/ HTML/?uri=CELEX:32006R0561\&qid=1621250039404\&from=SK

[3] Tapa Emea [online]. Available from: https://www.tapa-global.org/login.html?redirect_url=\%2Fiis.html

[4] HLATKA, M., STOPKA, O. STOPKOVA, M.: Proposal of innovative flooring options for marine containers. Nase More [online]. 2018, 65(4), p. 174-179. ISSN 0469-6255, eISSN 1848-6320. Available from: https://doi.org/10.17818/ NM/2018/4SI.2

[5] KONECNY, V., SEMANOVA, S., GNAP, J., STOPKA, O. Taxes and charges in road freight transport a comparative study of the level of taxes and charges in the Slovak Republic and the selected EU countries. Nase More [online]. 2018, 65(4), p. 208-212. ISSN 0469-6255, eISSN 1848-6320. Available from: https://doi. org/10.17818/NM/2018/4SI.8

[6] BARTUSKA, L., STOPKA, O., LIZBETIN, J. Methodology for determining the traffic volumes on urban roads in the Czech Republic. In: 19th International Scientific Conference on Transport Means 2015: proceedings. 2015. ISSN 1822-296X, p. 215-218.

[7] LAIMOS, P., CHRONOPOULOS, M., LAIMOU, CH. White paper route risk assessment methodology [online]. 2020. Available from: https://docplayer.net/196079896-White-paper-route-risk-assessment-methodology-securingyour-mobility-document-date-march-2020-address-information.html

[8] KUBASAKOVA, I., SULGAN, M., KUBANOVA, J.: Logistics for freight forwarding and road transport / Logistika pre zasielatelstvo a cestnu dopravu (in Slovak). 2. ed. Zilina: University of Zilina, EDIS, 2020. ISBN 978-80-554-1700-4.

[9] POLIAK, M., SIMURKOVA, P., CHEU, K.: Wage inequality across the road transport sector within the EU. Transport Problems [online]. 2019, 14(2), p. 145-153. eISSN 2300-861X. Available from: https://doi.org/10.20858/ tp.2019.14.2.13

[10] BYRNE, J. Disabilities in tertiary education. In: Voices of a margin. ROWAN, L., MCNAMEE, J. (ed.). Rockhampton: CQU Press, 1994. ISBN 1875902066.

[11] POLIAK, M., POLIAKOVA, A. Relation of social legislation in road transport on driver's work quality. In: Tools of Transport Telematics TST 2015 [online]. MIKULSKI, J. (ed.). Communications in Computer and Information Science, vol. 531. Cham: Springer, 2015. ISBN 978-3-319-24576-8, eISBN 978-3-319-24577-5, p. 300-310. Available from: https://doi.org/10.1007/978-3-319-24577-5_30

[12] SZYMANEK, A.: "Road Safety Sequence" - A New Concept of the Road Safety Management in Poland. Communications - Scientific Letters of the University of Zilina [online]. 2021, 23(1), p. F1-F10. ISSN 1335-4205, eISSN 2585-7878. Available from: https://doi.org/10.26552/com.C.2021.1.F1-F10

[13] Roadsec [online]. 2019. Available from: https://www.roadsec.eu/

[14] SIKOROVA, A., BESTA, P., DUBRAVOVA, P., PROSICKY, P., KISSOVA, K., MACHOVA, K.: Lack of stocks risk reduction. Acta Logistica [online]. 2017, 4(3), p. 9- 13. ISSN 1339-5629. Available from: https://doi.org/10.22306/ al.v4i3.8

[15] Time for action - Tapa Emea [online]. Available from: https://www.tapa-global.org/information/latest-news-views. html

[16] KAMPF, R., HLATKA, M., GROSS, P. Optimisation of distribution routes: a case study. Communications Scientific Letters of the University of Zilina [online]. 2021, 23(1), p. A62-A73. ISSN 1335-4205, eISSN 2585-7878. Available from: https://doi.org/10.26552/ com.C.2021.1.A62-A73 